\title{
Sarcoma pleomórfico de alto grau associado a metalose em paciente com artroplastia total do quadril* $^{*}$
}

\section{High-Grade Pleomorphic Sarcoma Associated with Metallosis in a Patient with Total Hip Arthroplasty}

\author{
Roni Serra Campos ${ }^{1(10}$ Walter Meohas ${ }^{20}$ Artur Shioji Ferradosa ${ }^{10}$ \\ Anneliese Fortuna de Azevedo Freire da $\operatorname{Costa}^{3(0)}$ João Antonio Matheus Guimarães ${ }^{3(1)}$ \\ Maria Eugenia Leite Duarte ${ }^{3(1)}$
}

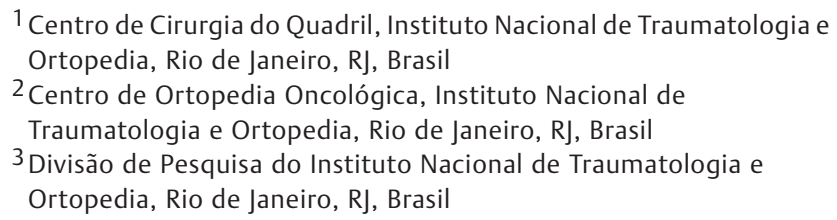

Endereço para correspondência Maria Eugenia Leite Duarte, MD, $\mathrm{PhD}$, Instituto Nacional de Traumatologia e Ortopedia, Rio de Janeiro, RJ 20940-070, Brasil (e-mail: meugenia.into@gmail.com).

Rev Bras Ortop

\section{Resumo \\ Palavra-Chave \\ - sarcoma \\ - artroplastia de quadril \\ - próteses de quadril \\ - metais}

Apesar da relação entre artroplastia de quadril e o desenvolvimento de sarcoma ter sido descrita pela primeira vez na literatura há cerca de quarenta anos, esta associação é extremamente rara. No presente relato de caso, descrevemos a associação entre implante ortopédico e sarcoma de partes moles em um homem de 79 anos submetido a artroplastia primária total do quadril (ATQ) por coxartrose há 24 anos. Foram descritas a evolução clínica e os achados radiográficos e histopatológicos da lesão. No intraoperatório da segunda cirurgia de revisão, foi evidenciada soltura dos componentes acetabular e femoral em associação com extensas áreas de necrose e de metalose. Foi realizado desbridamento da região do quadril e da coxa direita e retirada dos implantes. Devido à extensão da lesão e da necrose, não foi possível realizar nova reconstrução articular. O diagnóstico histopatológico de sarcoma pleomórfico indiferenciado de alto grau associado a extensas áreas de metalose foi estabelecido no tecido adjacente ao implante. O paciente evoluiu com metástases pulmonares e faleceu 6 meses após o diagnóstico. Apesar da raridade da associação, os sarcomas devem ser considerados no diagnóstico diferencial das solturas assépticas, particularmente na presença de metalose no tecido peri-implantar. Pelo nosso

Trabalho desenvolvido no Instituto Nacional de Traumatologia e Ortopedia, Rio de Janeiro, RJ, Brasil.

recebido 10 de Dezembro de 2020 aceito

2 de Junho de 2021
DOI https://doi.org/ $10.1055 / \mathrm{s}-0041-1735140$. ISSN 0102-3616. (c) 2021. Sociedade Brasileira de Ortopedia e Traumatologia. All rights reserved.

This is an open access article published by Thieme under the terms of the Creative Commons Attribution-NonDerivative-NonCommercial-License, permitting copying and reproduction so long as the original work is given appropriate credit. Contents may not be used for commercial purposes, or adapted, remixed, transformed or built upon. (https://creativecommons.org/ licenses/by-nc-nd/4.0/)

Thieme Revinter Publicações Ltda., Rua do Matoso 170, Rio de Janeiro, RJ, CEP 20270-135, Brazil 
Abstract
Keywords
- sarcoma
- arthroplasty, replacement, hip
- hip prosthesis
- metals

conhecimento o período de latência de 24 anos entre a ATQ primária e o estabelecimento do diagnóstico de sarcoma é um dos mais longos relatado até o momento.

Although the relationship between hip arthroplasty and the development of sarcoma was first described in the literature about forty years ago, this association is extremely rare. In the present case report, we describe the association between orthopedic implants and soft tissue sarcoma in a 79-year-old man who underwent primary total hip arthroplasty (THA) for coxarthrosis 24 years ago. In the present case report, we describe the clinical evolution and the radiographic and histopathological findings of the lesion. In the intraoperative period of the second revision surgery, loosening of the acetabular and femoral components in association with extensive areas of necrosis and metallosis was evidenced. We performed debridement of the hip and right thigh region and removed the implants. Due to the extent of the lesion and to necrosis, it was not possible to perform a new joint reconstruction. The histopathological diagnosis of highgrade undifferentiated pleomorphic sarcoma associated with extensive areas of metallosis was confirmed in tissue adjacent to the implant. The patient developed pulmonary metastases and died 6 months after the diagnosis. Despite the rarity of this association, sarcomas should be considered in the differential diagnosis of aseptic loosening, especially in the presence of metallosis in the peri-implant tissue. To our knowledge, the 24-year latency period between primary THA and the establishment of a sarcoma diagnosis is one of the longest reported to date.

\section{Introdução}

A resposta celular às partículas de debris provenientes da degradação de diversos tipos de materiais constitui a base biológica da osteólise peri-implantar que resulta nas falhas das artroplastias totais de quadril (ATQs). ${ }^{1}$ Os debris de desgaste dos componentes da prótese ativam o sistema monocítico/macrofágico, promovendo a liberação de citocinas próinflamatórias, particularmente de fatores de crescimento, de interleucinas e da proteína ligante do receptor ativador do fator nuclear kappa $\beta$ (RANKL, na sigla em inglês). A ação integrada destas moléculas de sinalização celular, e em particular a ativação da osteoclastogênese pela interação do RANKL com seu receptor ativador do fator nuclear kappa (RANK), iniciam o processo de osteólise. A ativação do sistema RANK/RANKL resulta no aumento do recrutamento e da atividade dos osteoclastos na interface com o implante, levando à reabsorção óssea e ao afrouxamento e à soltura da prótese. ${ }^{1}$

A relação entre artroplastia de quadril e o desenvolvimento de sarcoma foi relatada pela primeira vez em $1984 .^{2}$ Em uma revisão compreendendo um período de 30 anos (1974-2003), foi descrita a ocorrência de 46 tumores malignos (41 sarcomas, 4 linfomas e 1 carcinoma epidermóide) relacionados a $A T Q{ }^{3}$

\section{Relato do Caso}

Homem, branco, 79 anos, com coxartrose idiopática bilateral submetido a ATQ primária em 1992 (quadril direito) e 1993 (quadril esquerdo). Nas duas cirurgias, foi utilizado componente acetabular não cimentado composto por liga de titânio revestido em plasma poroso, fixado com parafusos acetabulares, núcleo acetabular de polietileno e haste femoral não cimentada, composta por liga de titânio e superfície rugosa proximal, recoberta por hidroxiapatia e cabeça intercambiável de cromo-cobalto. Em janeiro de 2001, o paciente apresentou soltura do componente acetabular do quadril esquerdo e foi submetido a artroplastia de revisão com troca por prótese acetabular não cimentada. Em setembro do mesmo ano, pelo mesmo diagnóstico, foi submetido a artroplastia de revisão do quadril direito com manutenção da haste e troca do acetábulo por componente cimentado. No intraoperatório dos dois procedimentos cirúrgicos, foram observados desgaste importante do polietileno e focos extensos de metalose no tecido peri-implantar. Em fevereiro de 2016, o paciente apresentou aumento de volume e dor intensa no quadril direito e dificuldade para deambular. Ao exame físico, apresentava aumento do volume da coxa sem flutuação, diminuição do arco de movimento e incapacidade de suportar carga no membro, sem déficit neurológico. Dois meses após o início dos sintomas, foi realizado novo procedimento de revisão no quadril direito, tendo como principal hipótese diagnóstica infecção e como diagnóstico diferencial lesão pseudotumoral por debris de metalose. No intraoperatório, foram evidenciadas soltura dos componentes acetabular e femoral e extensas áreas de necrose tecidual e de metalose envolvendo toda a região periarticular, sem evidência de secreção purulenta (-Figura 1). Foi realizado desbridamento da região do quadril e da coxa direita para retirada dos implantes e coleta de material para cultura microbiológica e avaliação histopatológica. Devido à 

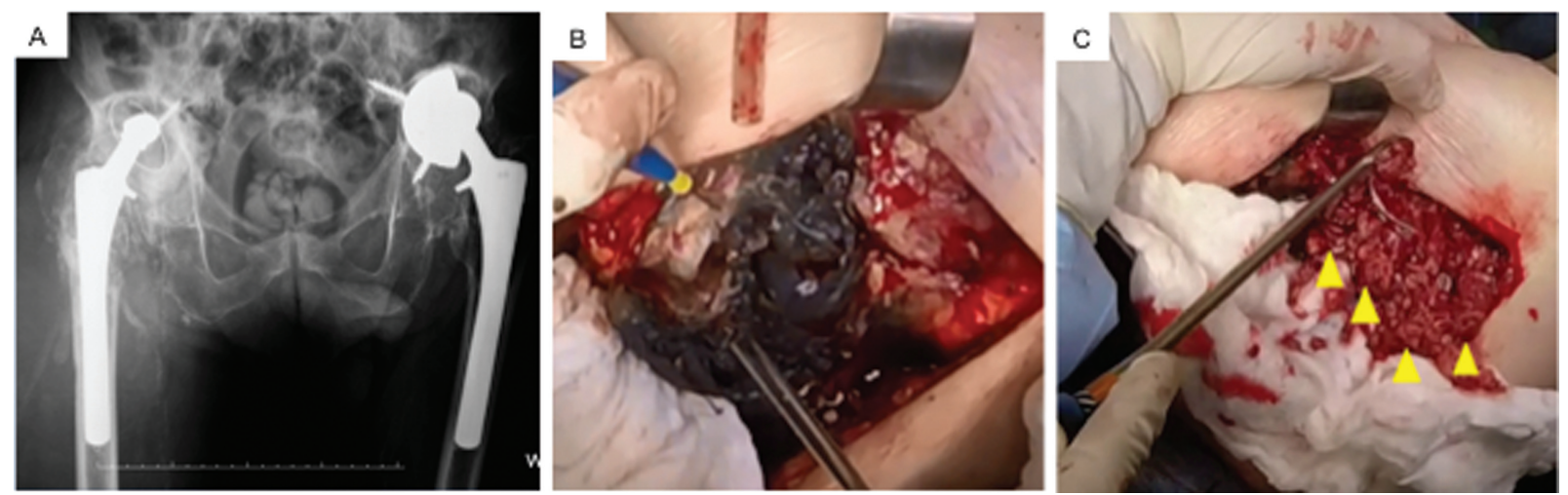

Fig. 1 Cirurgia de revisão do quadril direito em maio de 2016. (A) Radiografia panorâmica da bacia em incidência anteroposterior evidenciando artroplastia total bilateral de quadril. À direita, observa-se sinais de reabsorção proximal do fêmur e migração do componente acetabular para dentro do ilíaco, que apresenta osteólise difusa. Nota-se ainda importante aumento de volume de partes moles na região periprotética. A protése não cimentada à esquerda apresenta afrouxamento do componente acetabular, que se encontra medializado e verticalizado. $\mathrm{O}$ componente femoral está fixo. (B) Imagens do intraoperatório mostrando metalose (áreas enegrecidas). (C) Áreas extensas de necrose do tecido adjacente ao implante (setas) que foi desbridado para a retirada dos componentes acetabular e femoral, não sendo possível realizar nova reconstrução articular.

extensão da necrose tecidual, não foi possível realizar nova reconstrução articular. A avaliação histopatológica confirmou o diagnóstico de sarcoma pleomórfico indiferenciado (SPI) de alto grau e metalose ( - Figura 2). Os resultados das culturas microbiológicas intraoperatórias foram negativos. Em julho de 2016, a radiografia do quadril direito evidenciou volumosa massa tumoral em partes moles e extensa destruição do terço proximal do fêmur ( - Figura 3 ). 0 paciente evoluiu com perda de peso e dispneia, sendo diagnosticado derrame pleural e múltiplos nódulos metastáticos nos pulmões (-Figura 4), e faleceu em agosto de 2016, 24 anos após a realização da ATQ primária.
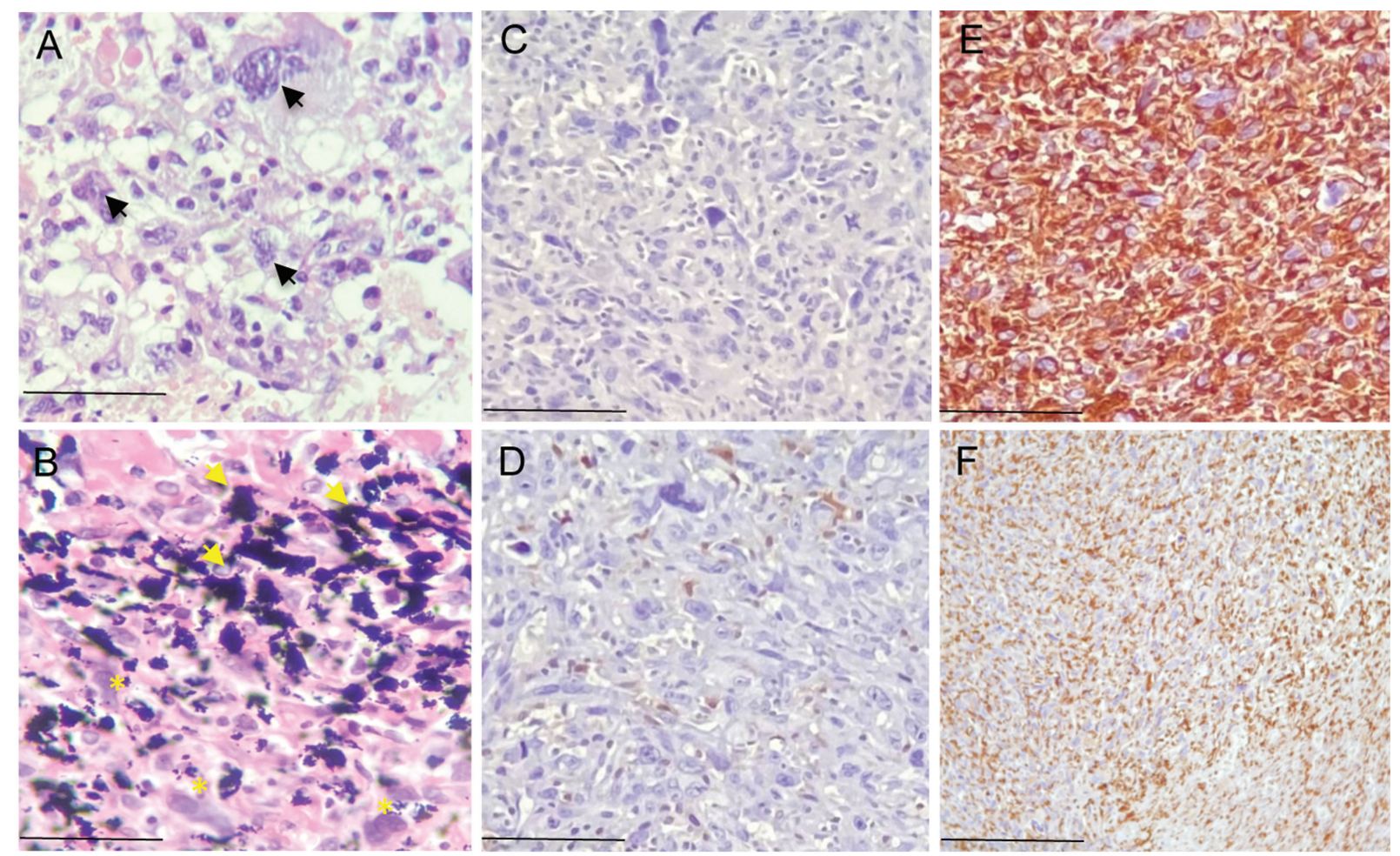

Fig. 2 Aspecto histopatológico e perfil imuno-histoquímico da lesão associada ao implante da articulação do quadril direito. (A) Sarcoma pleomórfico indiferenciado de alto grau caracterizado por grau acentuado de anaplasia celular (setas). (B) Debris de desgaste dos componentes da prótese identificado pelos pigmentos enegrecidos (setas) em associação com as células tumorais (*). (C) Ausência de imunomarcação para desmina. (D) Imunopositividade fraca para proteína S-100. (E) Expressão positiva difusa para os anticorpos anti-CD 68 e (F) Anti-Vimentina.

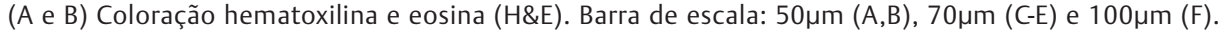




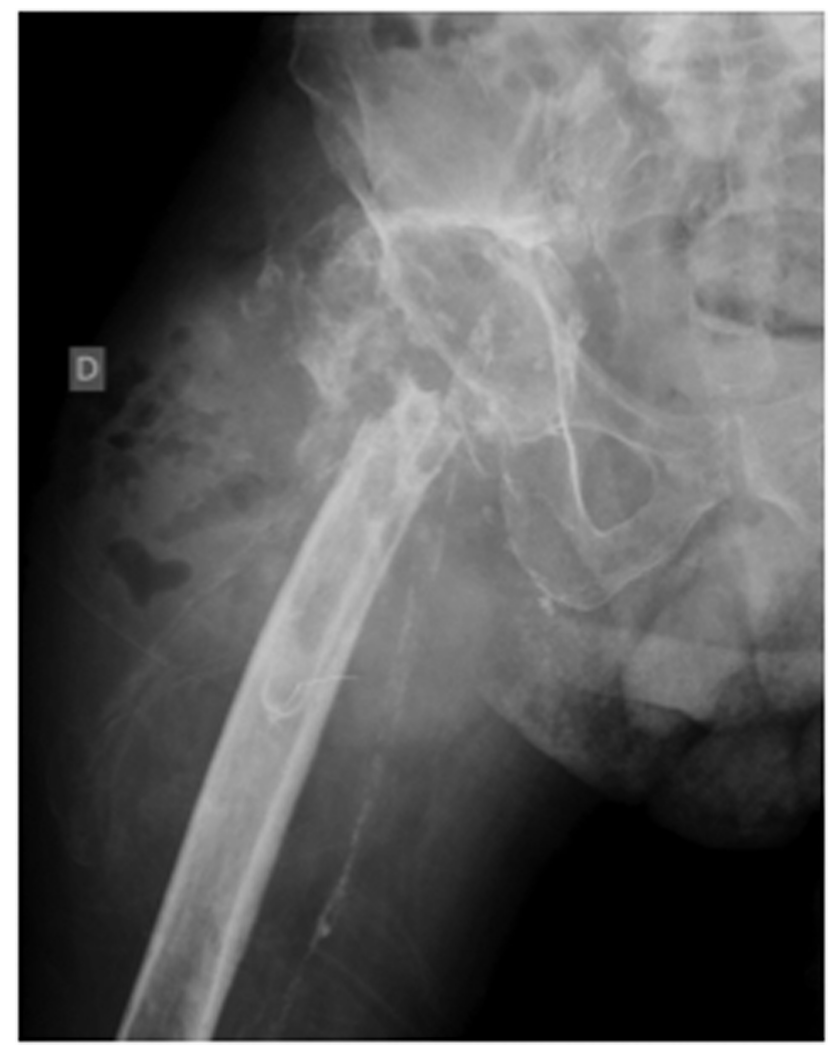

Fig. 3 Radiografia do quadril direito realizada em julho de 2016 após procedimento de artroplastia de revisão via acesso posterolateral com remoção dos componentes protéticos. Presença de volumosa massa tumoral em partes moles em associação com extensa destruição do terço proximal do fêmur.

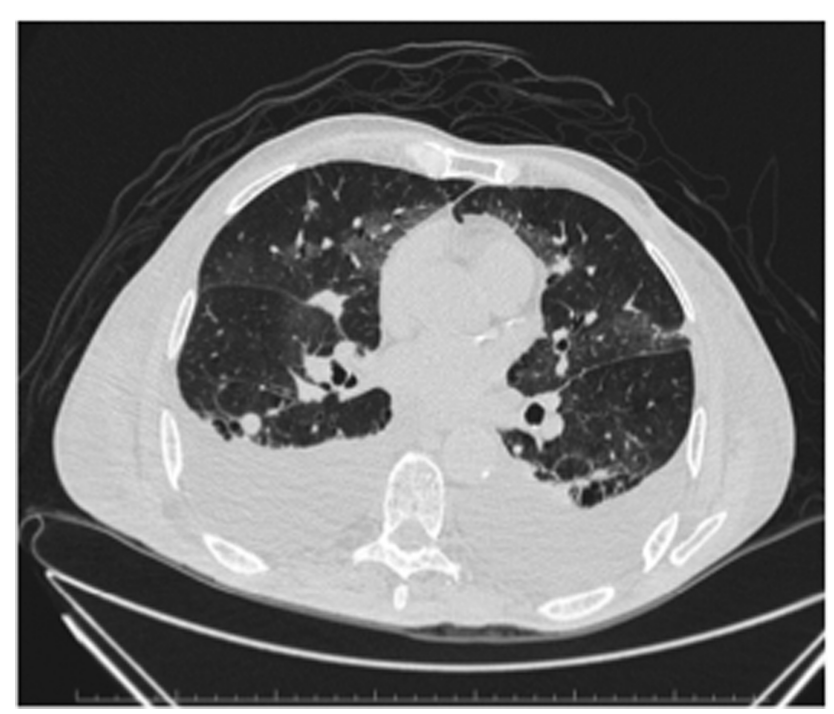

Fig. 4 Tomografia computadorizada do tórax. Em julho de 2016, o paciente apresentava derrame pleural e múltiplos nódulos metastáticos em ambos os pulmões e evoluiu para o óbito em agosto de 2016.

\section{Discussão}

As incidências de sarcomas de partes moles na população em geral e em associação com ATQ foram estimadas em entre 0,5 e 2,0 para cada 100.000 indivíduos por ano ${ }^{4}$ e em 1,43 para cada 100.000 indivíduos por ano, ${ }^{3}$ respectivamente. A associação a implantes mais frequente é com o SPI de alto grau (fibrohistiocitoma maligno, segundo a nomenclatura antiga). Contudo, a associação entre ATQ e outros sarcomas, como osteossarcomas, angiossarcoma e sarcoma sinovial também já foi descrita. ${ }^{5-7}$ Em um grande estudo populacional, foi demonstrado que os implantes de quadril metal-metal não estão associados a um risco geral aumentado de câncer ou morte por causa oncológica durante um período médio de acompanhamento de 7,4 anos. $^{8}$ Porém, neste estudo, não foram incluídos implantes do mesmo tipo utilizado no presente relato (polietileno-metal).

Considerando a data do início das queixas do paciente compatíveis com doença neoplásica (tumoração local, perda de peso e dispneia) com a confirmação histológica do diagnóstico de SPI, o intervalo de tempo entre a ATQ primária e o desenvolvimento da neoplasia foi de 24 anos. Este prazo é consideravelmente superior ao tempo médio de 6,7 anos ${ }^{3}$ para o desenvolvimento de sarcomas de partes moles relacionados com implantes ortopédicos.

A carcinogênese induzida por partículas de desgaste e corrosão de metais foi investigada in vitro através da exposição de fibroblastos a partículas de cobalto e cromo. As partículas dos metais promoveram a geração de espécies reativas de oxigênio que resultaram em aneuplodia, alterações cromossômicas, fragmentação mitocondrial e danos à rede de microtúbulos do citoesqueleto. ${ }^{9}$ No cenário clínico, apesar dos relatos sugerindo esta associação, o mecanismo através do qual as partículas de metais induzem a fibrose e estimulam a mutagênese no tecido periprotético ainda não foram estabelecidos. Em 2015, Sarhadi et al. verificaram anomalias genéticas no tecido periprotético, incluindo alterações em genes relacionados com o desenvolvimento de neoplasias malignas. Além disso, as anomalias genéticas mostraram associação com o maior período de contato do tecido com o implante. ${ }^{10}$

No presente relato, apresentamos um caso de associação de SPI de alto grau e ATQ realizada há 24 anos em um homem de 79 anos de idade submetido a ATQ bilateral. Considerando que a ATQ é o procedimento padrão-ouro para o tratamento da osteoartrite do quadril, realizado mundialmente em grande escala, a sua associação com o desenvolvimento de uma lesão maligna é um evento extremamente raro. Contudo, cirurgiões ortopédicos e radiologistas devem ser alertados e estar atentos para a possibilidade da associação entre alterações dos tecidos peri-implantares causadas por partículas de debris provenientes da degradação de implantes metálicos e o desenvolvimento de sarcomas em pacientes com afrouxamento de ATQ. Neste sentido, o diagnóstico precoce e o tratamento cirúrgico imediato podem evitar uma evolução insatisfatória, com o possível surgimento de metástases e um desfecho desfavorável para o paciente.

\section{Suporte Financeiro}

Não houve suporte financeiro de fontes públicas, comerciais, ou sem fins lucrativos.

\section{Conflito de Interesses}

Os autores declaram não haver conflito de interesses. 


\section{Referências}

1 Purdue PE, Koulouvaris P, Potter HG, Nestor BJ, Sculco TP. The cellular and molecular biology of periprosthetic osteolysis. Clin Orthop Relat Res 2007;454(454):251-261

2 Bagó-Granell J, Aguirre-Canyadell M, Nardi J, Tallada N. Malignant fibrous histiocytoma of bone at the site of a total hip arthroplasty. A case report. J Bone Joint Surg Br 1984;66(01):38-40

3 Visuri T, Pulkkinen P, Paavolainen P. Malignant tumors at the site of total hip prosthesis. Analytic review of 46 cases. J Arthroplasty 2006;21(03):311-323

4 Stiller CA, Botta L, Brewster DH, et al; EUROCARE-5 Working Group. Survival of adults with cancers of bone or soft tissue in Europe-Report from the EUROCARE-5 study. Cancer Epidemiol 2018;56:146-153

5 Lamovec J, Zidar A, Cucek-Plenicar M. Synovial sarcoma associated with total hip replacement. A case report. J Bone Joint Surg Am 1988;70(10):1558-1560
6 Kavalar R, Fokter SK, Lamovec J. Total hip arthroplasty-related osteogenic osteosarcoma: case report and review of the literature. Eur J Med Res 2016;21:8-13

7 Terrando S, Sambri A, Bianchi G, et al. Angiosarcoma around total hip arthroplasty: case series and review of the literature. Musculoskelet Surg 2018;102(01):21-27

8 Ekman E, Laaksonen I, Eskelinen A, Pulkkinen P, Pukkala E, Mäkelä K Midterm risk of cancer with metal-on-metal hip replacements not increased in a Finnish population. Acta Orthop 2018;89(05): 575-579

9 Raghunathan VK, Devey M, Hawkins S, et al. Influence of particle size and reactive oxygen species on cobalt chrome nanoparticle-mediated genotoxicity. Biomaterials 2013;34(14): 3559-3570

10 Sarhadi VK, Parkkinen J, Reito A, et al. Genetic alterations in periprosthetic soft-tissue masses from patients with metal-onmetal hip replacement. Mutat Res 2015;781:1-6 